\title{
SECAGEM DA POLPA DE GRAVIOLA PELO POCESSO FOAM-MAT E AVALIAÇÃO SENSORIAL DO PRODUTO OBTIDO
}

\author{
J. T.DIEB ${ }^{1}$, C. E. M. R.GURGEL ${ }^{2}$,T.N.P. DANTAS ${ }^{2}$ \\ e M. F. D deMEDEIROS ${ }^{1}$
}

${ }^{1}$ Universidade Federal do Rio Grande do Norte, Departamento de Engenharia Química

${ }^{2}$ Universidade Federal do Rio Grande do Norte, Programa de Pós-Graduação em Engenharia Química

E-mail para contato: judithdieb@gmail.com

\begin{abstract}
RESUMO -Foram realizados ensaios de secagem em camada de espuma da polpa de graviola com adição de $1 \%$ de emustab e $1 \%$ de liga neutra. Estudou-se os efeitos da temperatura $\left(50^{\circ} \mathrm{C}, 60^{\circ} \mathrm{C}\right.$ e $\left.70^{\circ} \mathrm{C}\right)$ e espessura da camada $(0,30 \mathrm{~cm}, 0,45$ $\mathrm{cm}$ e $0,60 \mathrm{~cm}$ ) na cinética de secagem, avaliando-se o comportamento das curvas de secagem e as características físico - químicas do produto em pó (umidade e atividade de água). Iogurtes saborizados com $7 \%$ de pó de graviola obtidos na secagem foram submetidas à análise sensorial que foi realizada mediante teste de avaliação utilizando 50 provadores não treinados. Cada provador emitiu notas para os atributos aparência, odor, sabor e textura. O produto apresentou índice de aceitabilidade superior a $70 \%$ e conforme a classificação qualitativa, as médias das notas ficaram compreendidas entre gostei ligeiramente e gostei regularmente (6,63 a 7,55 para os atributos odor e textura, respectivamente).
\end{abstract}

\section{INTRODUÇÃO}

A gravioleira (Annonamuricata L.),é uma das importantes frutíferas cultivadas no nordeste brasileiro. Atualmente, tem-se empregado novas tecnologias que permitem processar as frutas na forma de pó, fazendo com que estas, antes consumidas apenas em época de safra, passem a ser consumidas em qualquer período do ano.

Entre os processos estudados para a produção de polpas de frutas em pó destaca-se a desidratação em camada de espuma que tem como característica a rápida secagem de alimentos líquidos e pastosos como sucos, purê e polpas de frutas (MARQUES, 2009). Suas principais vantagens quando se compara com a secagem em spray são o baixo custo, menor temperatura de operação e tempo de processamento mais curto.

O líquido é transformado em espuma pela adição de pequena porção de um agente espumante e a incorporação de ar por agitação. Também são adicionados agentes estabilizantes para manter a estabilidade da espuma durante a secagem. A espuma é distribuída em camadas finas sobre bandejas e levada ao secador, em temperaturas relativamente baixas (menor ou igual a $70^{\circ} \mathrm{C}$ ). O produto desidratado é moído e convertido em pó (KADAM et al., 2010). 
Assim, este trabalho teve como objetivo verificar as características do produto obtido bem como sua aceitação sensorial em uma formulação de iogurte saborizado com o pó da graviola.

\section{MATERIAIS E MÉTODOS}

Os experimentos foram realizados tendo como variáveis independentes a espessura da camada de espuma e a temperatura de secagem da estufa. As variáveis respostas do processo foram a umidade do pó atingida após a secagem, determinada na balança de infravermelho, a atividade de água medida no analisador de atividade de água (AQUALAB), acidez total titulável obtida pela titulação com o $\mathrm{NaOH} 1 \mathrm{~N}$ e a solubilidade, retirando uma alíquota do sobrenadante após um processo de centrifugação.

\subsection{Preparação da espuma e secagem}

$\mathrm{Na}$ preparação da espuma para a secagem foram misturados em uma batedeira doméstica a polpa de graviola industrializada e os aditivos alimentícios (emustab e liga neutra) em uma proporção fixa de $1 \%(\mathrm{p} / \mathrm{p})$. A mistura permaneceu em agitação por, aproximadamente, 30 minutos para a formação de uma espuma porosa e estável. Análises de $\mathrm{pH}$, sólidos solúveis (Brix) e acidez total titulável (ATT) foram realizadas após a formação da espuma. As secagens foram realizadas nas temperaturas de 50,60 e $70^{\circ} \mathrm{C}$ variando também a espessura da espuma na placa de alumínio em 0,3, 0,45 e 0,6 cm. Para verificação da reprodutibilidade do processo a secagem na condição intermediária $\left(60^{\circ} \mathrm{C}\right.$ e $\left.0,45 \mathrm{~cm}\right)$ foi realizada em triplicata.

\subsection{Avaliação sensorial}

Iogurte natural do tipo adoçado foi saborizado com $7 \%$ de pó de graviola para ser submetido à análise sensorial realizada mediante teste de avaliação utilizando 50 provadores não treinados. Cada provador emitiu notas para os atributos aparência, odor, sabor e textura do iogurte. A avaliação sensorial foi realizada aplicando o teste de aceitabilidade com ficha contendo escala hedônica de 9 pontos, com 50 provadores não treinados, discentes e servidores da Universidade Federal do Rio Grande do Norte. Entre eles, 41 \% foram homens e $59 \%$ mulheres.

Cálculo do índice de aceitabilidade: $\mathrm{IA}(\%)=\mathrm{A} \times 100 / \mathrm{B}$, onde $\mathrm{A}=$ nota média obtida para o produto, e $\mathrm{B}=$ nota máxima dada ao produto. $\mathrm{O}$ IA com boa repercussão têm sido considerado $\geq 70 \%$

\subsection{Modelagem matemática}

O estudo de sistemas de secagem, seu dimensionamento, otimização e a determinação da viabilidade de sua aplicação comercial, podem ser feitos por simulação matemática. Para a simulação utilizam-se modelos matemáticos que representam satisfatoriamente a perda de umidade do produto em função do tempo durante o período de secagem. Neste trabalho foi utilizado o modelo de Page que é representado pela seguinte equação: 


$$
R U=\exp
$$

Onde:

$R U=$ Razão de umidade;

$k=$ constante da equação $(1 / \mathrm{min})$;

$\mathrm{n}=$ constante adimensional do modelo de Page;

$\mathrm{t}=$ tempo (min).

Para determinação dos parâmetros do modelo de Page, utilizou-se o software STATISTICA 7.0.

\section{RESULTADOS E DISCUSSÕES}

A tabela 1 caracteriza a espuma quanto a sua expansão após o período de batimento relacionando a densidade da espuma com a densidade da polpa da fruta. Os resultados de expansão $>100 \%$ viabilizam o processo de secagem em camada de espuma sabendo que a transferência de calor e massa é favorecida pela maior área de contato. Também foi determinado o teor de sólidos solúveis (Brix) contido na amostra

Tabela 1 - Caracterização da espuma

\begin{tabular}{lcccc}
\hline & $\rho_{\text {espuma }}(\mathrm{g} / \mathrm{ml})$ & $\rho_{\text {polpa }}(\mathrm{g} / \mathrm{ml})$ & Expansao(\%) & Brix \\
\hline Ensaio 5 & 0,51 & 1,03 & 101,96 & 12,24 \\
Ensaio 6 & 0,5 & 1,03 & 106,00 & 12,15 \\
Ensaio 7 & 0,45 & 1,03 & 128,89 & 12,33 \\
\hline
\end{tabular}

Os gráficos ilustrados nas Figuras 1(a) e 1(b) representam os dados experimentais e preditos pelo modelo de Page para todas as condições de secagem estudadas. Conforme se observa, as curvas ajustadas pelo modelo de Page representam satisfatoriamente os dados experimentais. Na figura 1(a), observa-se o efeito da temperatura e da espessura da camada de espuma no processo de secagem, temperatura mais elevadas e espessuras mais finas aceleram a secagem. Na temperatura de $70^{\circ} \mathrm{C}$ e espessura de $0,30 \mathrm{~cm}$ foi observado o menor tempo de secagem.

A reprodutibilidade do processo na condição intermediária, figura1(b), não foi muito bem retratada embora o modelo tenha se ajustado satisfatoriamente aos dados experimentais. A pequena variação das curvas pode ser justificada pela diferença de densidade entre as espumas que foram preparadas, que variaram entre $0,45 \mathrm{~g} / \mathrm{ml}$ (ensaio7)e $0,51 \mathrm{~g} / \mathrm{ml}$ (ensaio5), conforme consta na Tabela 1. As espumas menos densas proporcionam maiores taxas de secagem uma vez que a maior porosidade favorece as condições para a transferência de calor e de massa.

Na tabela 2 são exibidos os parâmetros do Modelo de Page. Conforme se observa há um bom ajuste do modelo aos dados experimentais com $\mathrm{R}^{2}>0,99$. As constantes de secagem 
também foram influenciadas pela temperatura e espessura da camada e apresentam resultados compatíveis com a literatura (Madureira (2011) e Figueirêdo (2013)).

Figura 1- Curvas da razão de umidade em função do tempo, dados experimentais e preditos pelo Modelo de Page para temperaturas de 50 e $70^{\circ} \mathrm{C}$ com e espessuras de $0,3 \mathrm{~cm}$ e $0,6 \mathrm{~cm}$ (a), e nas condições do ponto central, $60^{\circ} \mathrm{C}$ e $0,45 \mathrm{~cm}$ de espessura (b).

(a)

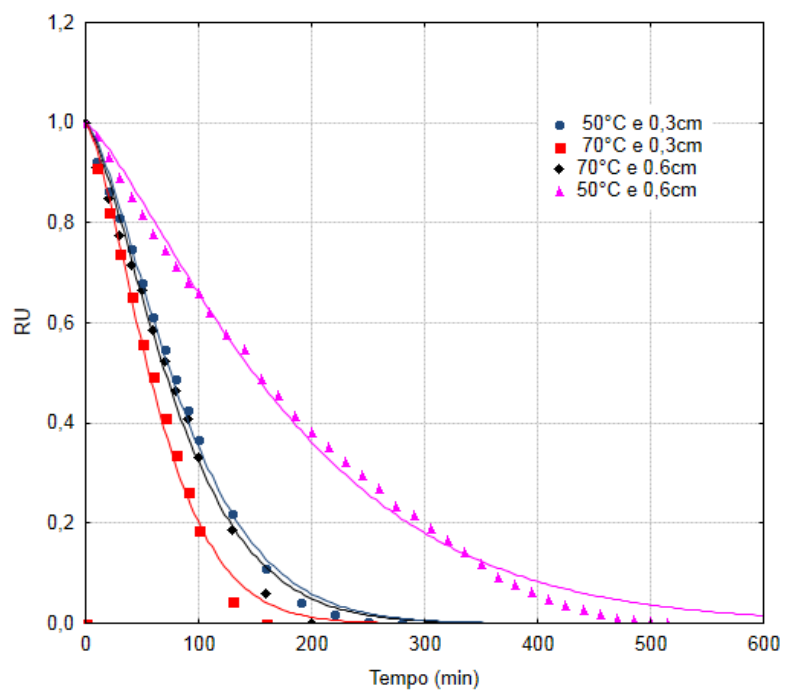

(b)

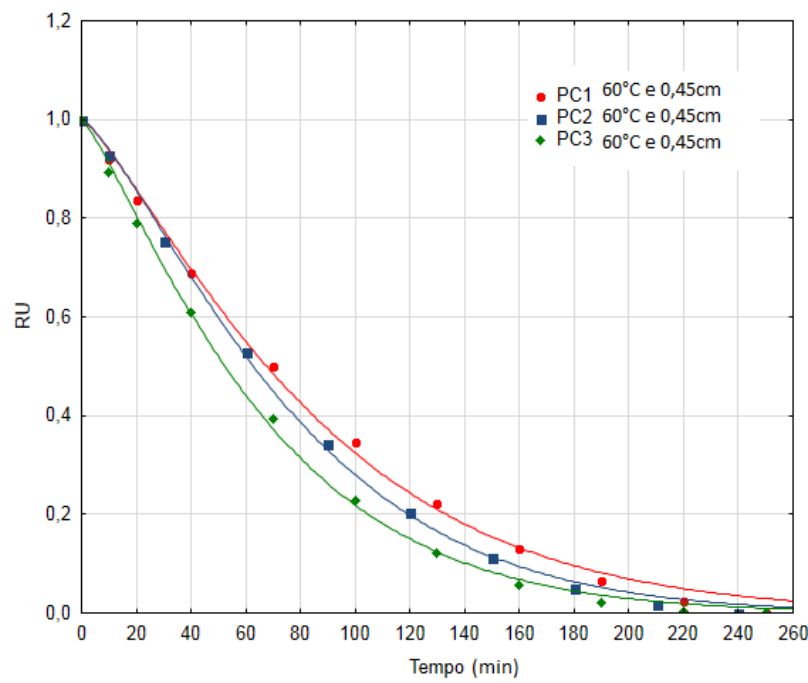

Tabela 2 - Parâmetros do Modelo de Page

\begin{tabular}{cccccc}
\hline Ensaios & $\mathbf{T}\left({ }^{\circ} \mathbf{C}\right)$ & Espessura (cm) & $\mathbf{K}\left(\mathbf{m i n}-{ }^{\mathbf{1}}\right)$ & $\mathbf{n}$ & $\mathbf{R}^{\mathbf{2}}$ \\
\hline $\mathbf{1}$ & 50 & 0,30 & 0,00138 & 1,438 & 0,998 \\
$\mathbf{2}$ & 70 & 0,30 & 0,00325 & 1,486 & 0,997 \\
$\mathbf{3}$ & 50 & 0,60 & 0,00110 & 1,286 & 0,997 \\
$\mathbf{4}$ & 70 & 0,60 & 0,00174 & 1,407 & 0,994 \\
$\mathbf{5}$ & 60 & 0,45 & 0,00366 & 1,244 & 0,997 \\
$\mathbf{6}$ & 60 & 0,45 & 0,00302 & 1,313 & 0,999 \\
$\mathbf{7}$ & 60 & 0,45 & 0,00570 & 1,213 & 0,998 \\
\hline
\end{tabular}

Os pós obtidos da secagem em camada de espuma foram caracterizados e as informações encontram-se dispostas na tabela 3. Apresentaram umidades variando de 3,36 até 6,61\%, atividade de água na faixa consideradaapropriada para o armazenamento e com pouca probabilidade de proliferação de microorganismos.Segundo Araújo (2001), a estabilidade do alimento com atividade de água (aw) entre 0,2 e 0,4é elevada, não sendo necessário o uso de conservantes para controlar o crescimento de microrganismos. A acidez total realizada por titulação apresentou pouca variação em seus valores e o produto também apresentou elevada solubilidade em água tendo seus valores compatíveis com Dantas (2010) que utilizando o método de camada de espuma encontrou solubilidades de $98 \%$ e $91 \%$ para os pós de abacaxi e manga, respectivamente. 
Tabela 3 - Caracterização da polpa de graviola em pó

\begin{tabular}{ccccccc}
\hline Ensaios & $\mathbf{T}\left({ }^{\circ} \mathbf{C}\right)$ & Espessura (cm) & Umidade(\%) & aw pó & ATT (\%) & Solubilidade (\%) \\
\hline $\mathbf{1}$ & 50 & 0,30 & 6,61 & 0,322 & 5,34 & 80,70 \\
$\mathbf{2}$ & 70 & 0,30 & 3,36 & 0,256 & 5,30 & 83,77 \\
$\mathbf{3}$ & 50 & 0,60 & 4,95 & 0,287 & 5,56 & 86,98 \\
$\mathbf{4}$ & 70 & 0,60 & 4,38 & 0,281 & 5,33 & 82,10 \\
$\mathbf{5}$ & 60 & 0,45 & 5,10 & 0,280 & 5,60 & 75,65 \\
$\mathbf{6}$ & 60 & 0,45 & 6,00 & 0,312 & 5,54 & 77,90 \\
$\mathbf{7}$ & 60 & 0,45 & 5,26 & 0,254 & 5,64 & 78,37 \\
\hline
\end{tabular}

Com relação à avaliação sensorial do iogurte saborizado com o pó de graviola, todos os atributos apresentaram índice de aceitação (IA) superior a 70\% (figura 2(b)), indicando que o produto teve boa aceitação entre os provadores. A menor média obtida foi no quesito odor $(6,4)$ compreendida entre gostei ligeiramente e gostei regularmente enquanto que a maior média foi no quesito textura $(7,5)$ que está entre gostei regulamente e gostei muito, figura 2(a).De uma forma geral, apesar de se esperar que o processo de secagem modifique características como cor, aparência e sabor, o produto não teve sua aceitação comprometida.

Figura 2- Gráficos indicativos da avaliação sensorial. Média das notas para cada quesito (a) e Índice de aceitação(\%) (b)

(a)

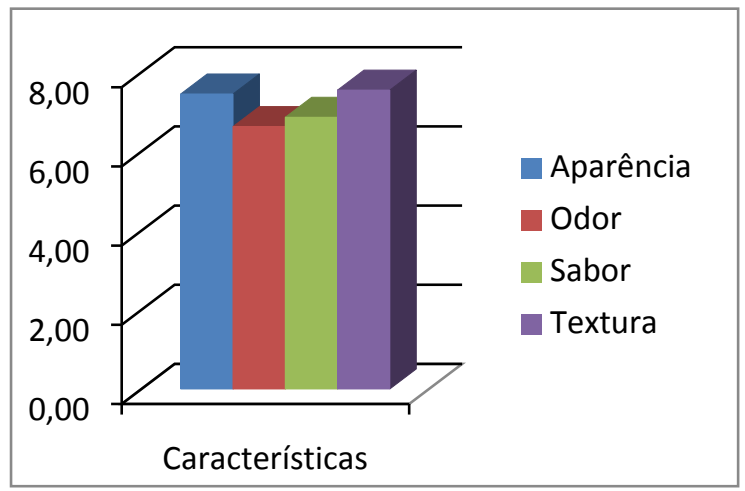

(b)

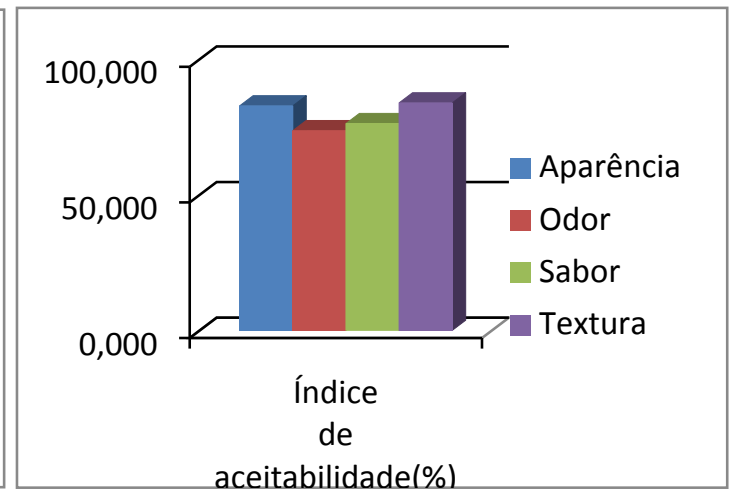

\section{CONCLUSÕES}

De uma forma geral, os resultados encontrados para a secagem da polpa de graviola foram satisfatórios uma vez que o pó obtido apresentou boas condições para conservação e armazenamento. O modelo de Page apresentou um bom ajuste aos dados experimentais da razão de umidade em função do tempo podendo ser utilizado para representar a cinética de secagem da polpa de graviola em camada de espuma.

Os resultados demonstram que o iogurte saborizado com o pó de graviola teve uma boa aceitação sensorial podendo ser uma alternativa viável para o enriquecimento alimentos com a 
graviola, cujas características nutricionais e medicinais constitui-se um grande apelo ao mercado consumidor de alimentos saudáveis..

\section{REFERÊNCIAS}

DANTAS, S.C.M. Desidratação de polpas de frutas pelo método foam-mat. Natal: 2010, 86 p. (Dissertação de Mestrado).

FIGUEIRÊDO et al. Cinética de secagem em camada de espuma da polpa de mangaba. VII Congreso Ibérico de Agroingenieria y Ciencias Hortícolas, Madrid, Agosto 2013.

KADAM, D.M.; PATIL, R.T.; KAUSHIK, P. Foam Mat Drying of Fruit and VegetableProducts. In: Drying of Foods, Vegetables and Fruits, v.1, p.111-124, Singapure, 2010.

MADUREIRA, I.A.; FIGEIRÊDO, R.M.F.; QUEIROZ, A.T.M,; FILHO, E.D.D. Cinética de secagem da Polpa do Fígo-da índia. Revista Brasileira de Produtos Agroindustriais, Campina Grande, v.13, n Especial, p. 345- 354, 2011

MARQUES, G.M.R, Secagem do caldo de cana em leito de espuma e análise sensorial do produto. 2009. 84f. Dissertação (Mestrado em Engenharia de Alimentos). Universidade Estadual do Sudoeste da Bahia. Itapetinga - BA 